\title{
Accounting for climate ills
}

\section{With warming expected to worsen public health problems, policymakers are being urged to fight disease and climate change simultaneously. Brian Hoyle reports.}

$\mathrm{n}$ the latest of the charges against climate change, experts are now calling for policymakers to recognize its role in damaging human health, and are highlighting the need for smart policies that will simultaneously benefit human well-being and mitigate global warming.

To date, the most notorious of climate's public health transgressions, and the most controversial, has been its involvement in the alarming spread of malaria in Africa and elsewhere. But the health effects of a warming world will not be restricted to tropical nations and virulent pathogens. Other likely impacts that are equally dangerous, if perhaps less daunting, are the increased risk of respiratory diseases and metabolic disorders owing to poor air quality and rising temperatures.

A recent wave of activity has focused on these issues, beginning with the International Conference on Emerging Infectious Diseases in Atlanta, Georgia, in mid-March. Since then, public health bodies have begun to take the problem to heart. On 31 March, the American Public Health Association released a blueprint for combating the health impacts of climate change. This was followed by World Health Day on 7 April, which took global warming as its theme. But perhaps most significant step in adding human disease to the list of climate-related ills was the decision by White House officials to allow the US Centers for Disease Control and Prevention (CDC) to give complete testimony on the topic to Congress on 9 April, having previously redacted the same speech last October amid a torrent of controversy.

Speaking last March at the Atlanta conference, Howard Frumkin of the CDC, who delivered the April testimony to Congress, said, "The new world of public health must seize the opportunities to respond to climate change in ways

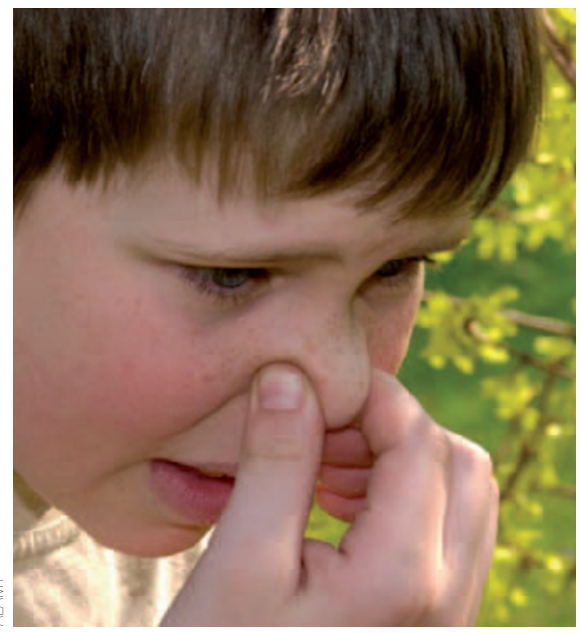

Allergies are expected to increase as temperatures rise.

that benefit both the atmosphere and people's health." The same view holds in the United Kingdom, where, according to Paul Wilkinson of the London School of Hygiene \& Tropical Medicine, "public health specialists and researchers have for some time been describing the links between climate change, health and policy in the transport, energy, agricultural, housing and other sectors."

On both sides of the Atlantic, the ideal is similar: to address climate, energy and health issues through intuitive and mutually beneficial policies. For example, encouraging 'active transport' - walking and cycling - as an alternative to driving would enable people to cut their carbon footprint while lowering their cholesterol and curbing air pollution to boot.

"The current buzz word is 'co-benefits' - the notion that mitigation will not only help to reduce distant adverse health effects by attempting to limit climate change, but also that it will deliver immediate, usually positive, effects," says Wilkinson.
What's needed, says Frumkin, is "the courage to paddle upstream" into the turf of other agencies, where many of the real determinants of public health reside. "We need to get more comfortable working with those who make policies regarding transportation, energy, building construction, and so on, because those are the very places where health-relevant decisions are made," he explains.

Some small steps indicate the issue is gaining traction in the United States. A bipartisan resolution introduced in April in the US Senate has acknowledged the crucial relationship between public health and climate change, and the Senate Committee on Health, Education, Labor and Pensions, chaired by Edward Kennedy, has plans underway to conduct further hearings on the issue.

Despite recognition of the climate-health connection in Europe, less ground has been gained. Taking Britain as an example, "In broad terms, the UK administration sets a high priority to tackling climate change, but most of the current debate is driven by considerations other than health," says Wilkinson. In a report entitled 'Protecting health in Europe from climate change' and released on World Health Day, the World Health Organization urged the European Union to respond to ills that will be worsened by global warming.

There may be long way to go before the sidewalks are crowded and the roads sparsely travelled, but, says Wilkinson, "It isn't fanciful to think that many people will be ready to adopt more sustainable and healthier lifestyles if given the right opportunities and incentives."

Published online: 8 May 2008

doi:10.1038/climate.2008.43

Brian Hoyle is a freelance writer and editor based in Nova Scotia, Canada. 